\title{
Interplay of seismic and a-seismic deformation during the 2020 sequence of Atacama, Chile.
}

\author{
E. Klein ${ }^{1, *}$, B. Potin ${ }^{2}$, F. Pasten-Araya ${ }^{2}$, R. Tissandier ${ }^{3}$, K. Azua $^{2}$, Z. Duputel ${ }^{4}$, C. Herrera ${ }^{5}$, \\ L. Rivera ${ }^{4}$, J.M. Nocquet ${ }^{3,6}$, J.C. Baez ${ }^{7}$, D. Zigone ${ }^{4}$, R. Madariaga ${ }^{1,2}$, J.P. Ampuero ${ }^{6}$, S. \\ Ruiz $^{2}$, C. Vigny ${ }^{1}$
}

\footnotetext{
${ }^{1}$ Laboratoire de géologie - CNRS UMR 8538, Ecole normale supérieure - PSL University, Paris, France

${ }^{2}$ Departamento de Geofísica, Universidad de Chile, Santiago, Chile

${ }^{3}$ Université de Paris, Institut de Physique du Globe de Paris, CNRS, F-75005 Paris, France

${ }^{4}$ Institut Terre et Environnement de Strasbourg, Université de Strasbourg/EOST/ENGEES, CNRS UMR 7063, 5 rue Descartes, Strasbourg F-67084, France

${ }^{5}$ School of Earth and Ocean Sciences, University of Victoria, 3800 Finnerty Road, Victoria, British Columbia V8P 5C2, Canada

${ }^{6}$ Université Côte d'Azur, IRD, CNRS, Observatoire de la Côte d'Azur, Géoazur, 250 rue Albert Einstein, Sophia Antipolis, 06560 Valbonne, France

${ }^{7}$ Centro Sismológico Nacional Universidad de Chile Blanco Encalada 2002 Santiago CP 8370449, Chile
}

\begin{abstract}
An earthquake sequence occurred in the Atacama region of Chile throughout September 2020. The sequence initiated by a mainshock of magnitude $M_{w}=6.9$, followed 17 hours later by a $M_{w}=6.4$ aftershock. The sequence lasted several weeks, during which more than a thousand events larger than $M_{l}=1$ occurred, including several larger earthquakes of magnitudes between 5.5 and 6.4. Using a dense network that includes broad-band, strong motion and GPS sites, we study in details the seismic sources of the mainshock and its largest aftershock, the afterslip they generate and their aftershock, shedding light of the spatial temporal evolution of seismic and aseismic slip during the sequence. Dynamic inversions show that the two largest earthquakes are located on the subduction interface and have a stress drop and rupture times which are characteristics of subduction earthquakes. The mainshock and the aftershocks, localised in a 3D velocity model, occur in a narrow region of interseismic cou-
\end{abstract}

Corresponding author: E., Klein, klein@geologie.ens.fr 
pling (ranging 40\%-80\%), i.e. between two large highly coupled areas, North and South of the sequence, both ruptured by the great $M_{w} \sim 8.51922$ megathrust earthquake. High rate GPS data $(1 \mathrm{~Hz})$ allow to determine instantaneous coseismic displacements and to infer coseismic slip models, not contaminated by early afterslip. We find that the total slip over 24 hours inferred from precise daily solutions is larger than the sum of the two instantaneous coseismic slip models. Differencing the two models indicates that rapid aseismic slip developed up-dip the mainshock rupture area and down-dip of the largest aftershock. During the 17 hours separating the two earthquakes, micro-seismicity migrated from the mainshock rupture area up-dip towards the epicenter of the $M_{w} 6.4$ aftershocks and continued to propagate upwards at $\sim 0.7 \mathrm{~km} / \mathrm{day}$. The bulk of the afterslip is located up-dip the mainshock and down-dip the largest aftershock, and is accompanied with the migration of seismicity, from the mainshock rupture to the aftershock area, suggesting that this aseismic slip triggered the $M_{w}=6.4$ aftershock. Unusually large post-seismic slip, equivalent to $M_{w}=6.8$ developed during three weeks to the North, in low coupling areas located both up-dip and downdip the narrow strip of higher coupling, and possibly connecting to the area of the deep Slow Sleep Event detected in the Copiapo area in 2014. The sequence highlights how seismic and aseismic slip interacted and witness short scale lateral variations of friction properties at the megathrust. 


\section{Key Words:}

Chilean subduction zone, Atacama, earthquake sequence, GPS, post seismic, seismology

\section{Introduction}

The Atacama region $\left(26^{\circ} \mathrm{S}-30^{\circ} \mathrm{S}\right)$ is one of the long lasting seismic gaps of Chile [ Lomnitz, 2004; Métois et al., 2016; Ruiz and Madariaga, 2018]. In this region, the last megathrust earthquake occurred in 1922, a $M_{w} 8.6$ event that stroke North-Central Chile and triggered a transpacific tsunami [Willis, 1929; Beck et al., 1998; Soloviev and Go, 1976; Ruiz and Madariaga, 2018; Kanamori et al., 2019]. After 1922, the largest earthquake that occurred in the area was in 1983 with a magnitude 7.7 [Pacheco and Sykes, 1992; Comte et al., 1992]. More recently, in 2013, an event of magnitude 6.8 located around $50 \mathrm{~km}$ depth occurred, probably at the bottom-end of the seismogenic zone along the plate interface. A decade of survey GPS measurements conducted in this region revealed two large highly coupled zones, the Atacama and the Chañaral segments, separated by a relatively large intersegment of intermediate to low coupling, named the Baranquilla low coupling zone (LCZ) [Métois et al., 2013; Métois et al., 2016; Klein et al., 2018a]. Additionally, a 1.5 year-long, $M_{w} \sim 7$, slow slip event (SSE) was also detected in the region in 2014, but occurred deeper $(40-60 \mathrm{~km})$ than usual seismogenic depths $(10-40 \mathrm{~km})$ [Klein et al., 2018b]. A detailed analysis of the only continuous GPS site in the region at this time also revealed two episodes of transient deformation, prior to the 2014 event, in 2005 and 2009, suggesting a possible recurrence of about 5-years for deep slow slip events in the region [Klein et al., 2018b].

Here, we study a large seismic sequence that occurred in the Atacama region throughout September 2020 (Fig. 1), South of an area where seismic swarms have occurred several times in the past, i.e. in 1973, 1976 and 2016, offshore the town of Caldera [ $27^{\circ} \mathrm{S}$, Fig. 1, Comte et al., 2002; Holtkamp et al., 2011]. The 2020 sequence initiated on September, $1^{\text {st }}$, at 04:09 UTC, with an earthquake of magnitude 6.9. It was followed 20 minutes later by an event of magnitude 6.3, close to the mainshock epicenter and 17 hours later, at 21:09 UTC, by another event of magnitude 6.4 , the largest aftershock of the entire sequence, $20 \mathrm{~km}$ updip the mainshock. Overall, the sequence lasted several weeks with more than a thousand events and includes several large earthquakes of magnitude larger than 5. We use a complete set of seismological sites deployed in the area prior to the sequence that includes broad-band, strong motion and GPS to monitor the spatio-temporal evolution of this sequence (Fig. 1). 
Thanks to this dense network we greatly improve the threshold detection down to magnitude 1 (with a magnitude of completeness of 2.5) and the precision of the localisation through a 3-D refined velocity model. Focusing on the first day, we compare the high rate and the daily GPS solutions to quantify the amount of seismic and aseismic deformation that took place after the mainshock. Finally, we discuss how this sequence takes place in the earthquakes history of this area and how it may alter the potential seismic hazard of the nearby highly coupled zones.

\section{Seismic analysis}

The Atacama region is poorly covered by the national seismic network (CSN, Centro Sismológico Nacional, University of Chile, Santiago) with only 2 broad-band stations at less than $100 \mathrm{~km}$ from the sequence. Since 2013, less than 2000 earthquakes have been located in Chile between latitudes $30^{\circ} \mathrm{S}$ and $26^{\circ} \mathrm{S}$.

\subsection{Building the sequence catalogue}

We built a catalogue using data from 14 broad-band stations of the CSN in a $300 \mathrm{~km}$ radius around the sequence, completed by data from three semi-permanent stations in the Copiapo region (30-150 km North), 10 temporary stations between Vallenar and Ovalle (100-300 km South), and 30 stations from the national strong-motion network of the CSN [Barrientos, 2018; Leyton et al., 2018] providing data only for the 16 largest events (Fig. 1). Event detection was performed by STA/LTA method using the six closest stations, with two constraints: firstly, one of the three closest stations had to be first in triggering a detection and secondly, each event had to trigger detections on at least 5 stations to be considered. These criteria geographically restricted the area of study and filtered out the smallest local events and the hundreds of earthquakes happening everyday in Chile. Between the $25^{\text {th }}$ of August and the $25^{\text {th }}$ of September included, 1354 events have been detected, out of which $50 \%$ happened within the first four days of the sequence. No significant raise in seismic activity was detected prior to the main event: 1 to 9 events/day occurred between the $25^{\text {th }}$ and the $31^{\text {st }}$ of August (Fig. 1-B). Manual P- and S-wave arrival-times readings were performed, leading to 916 earthquake locations out of which 843 events belong to the dense core of the sequence and 74 correspond to surrounding activity that may or may not be related to the sequence. Specifically, half of these (35 events) occur up North in a $80 \times 80 \mathrm{~km}^{2}$ area, 11 are 
located further inland, 15 are poorly located beyond the trench or very deep below the contact and the last 13 correspond to quarry blasts.

Earthquake locations were determined by a double-difference approach in a regional 3D velocity model obtained by regional tomography [Potin et al., 2019]. Figure 2 represents a trench-perpendicular vertical cross-section across the sequence, with P-wave velocities and P- over S-wave velocity ratios [based on earthquakes arrival times, Potin et al., 2019]. The seismicity associated with the sequence is located at the interface, mainly between $15 \mathrm{~km}$ and $40 \mathrm{~km}$ deep, with some events scattered within the first $15 \mathrm{~km}$ of the upper plate. The background seismicity visible on Fig. 2, located within a $50 \mathrm{~km}$ range on both sides of the crosssection, appears to extend within the plunging oceanic plate and can be interpreted as the double seismic zone observed in several places along the Chilean coast [Bloch et al., 2014, 2018; Comte and Suarez, 1994; Sippl et al., 2018], although these events are poorly located due to the lack of local observations. P-wave velocities and P- over S-wave velocity ratios for the upper plate, the interface and the upper oceanic mantle are consistent with others local tomographic models obtained in northern Chile [Pastén-Araya et al., 2018, 2021].

Figure 3 shows the spatio-temporal evolution of the seismicity over the first $72 \mathrm{~h}$ following the mainshock. Immediately after the mainshock, seismicity spread over a 20 x $20 \mathrm{~km}^{2}$ region, a size roughly consistent with the rupture area (Fig. 3-C and 3-D). This initial spatial extension shows the area of influence of the stress increase due to the mainshock. Throughout these first 72 hours, both the North-South and Eastern (downdip) boundaries of seismicity remain stable. On the contrary, seismicity slowly spreads updip (westward), with an average velocity of approximately $\sim 0.7 \mathrm{~km} /$ hour (considering a dip of $20^{\circ}$; red dashed line on Fig. 3-C), resulting in almost doubling the initial area of aftershock.

\subsection{Moment magnitudes}

To constrain the magnitude of the largest events of the sequence, we perform regional W-phase source inversions [Duputel et al., 2012] combined with a bootstrap analysis [Efron and Tibshirani, 1993]. We use broad-band velocimetric data from the Federation of Digital Seismic Networks (FDSN) (C, C1 (doi .org/10.7914/SN/C1), CX (doi : 10.14470/ PK615318), G (doi : 10.18715/GEOSCOPE.G), GT (doi . org/10.7914/SN/GT) and II (doi .org/10.7914/SN/II) networks) within 26 degrees of epicentral distance. To improve the homogeneity of the data coverage, we select one station per cell in a $100 \mathrm{~km} \times$ 
$100 \mathrm{~km}$ grid in the vicinity of the source. The used time window starts at the P-wave arrival time. Its duration is $300 \mathrm{~s}$ for epicentral distances smaller than $12^{\circ}$ and grows with distance $(15 \times \Delta s / 0)$ for farther stations. Waveforms are filtered using a frequency band-pass that varies with the Global CMT magnitude. Here we filter between 50-80 s and 120-250 s. The average $M_{w}$ and $\pm 2 \sigma$ uncertainties are: $6.87 \pm 0.07,6.29 \pm 0.04,6.42 \pm 0.07$ for the events that occurred on 2020/09/01 at 04:09 UTC, 04:30 UTC and 21:09 UTC. The bootstrap histograms are shown on Fig. 4 and estimated parameters are gathered in the supporting information.

\subsection{Characterisation of the sequence: Mainshock-Aftershock sequence or Seismic swarm ?}

To evaluate the difference of the 2020 Atacama seismicity compared to a standard mainshock-aftershock sequence, we analyze earthquake sizes and temporal distribution in the area. Considering seismic events in the epicentral area since 2017 in the CSN catalog, we estimate a b-value of $b=0.8 \pm 0.2$ using the Aki [1965] approach (consistently, we estimate $b=0.7 \pm 0.1$ for the 2020 Atacama sequence using the catalog presented in section 2.1). The time of aftershocks relative to the $M_{w}=6.9$ mainshock is consistent with the Omori-Utsu law $r(t)=K(t+c)^{-p}$ with $p=1.0, c=0.1$ days and $K=16.3$ [see Fig. S1 of the Supporting Information; Omori, 1894; Utsu, 1957]. Looking independently into the magnitude and temporal distribution of the earthquakes, the sequence does not seem different from a classical mainshock-aftershock sequence. However, what seems anomalous is the occurrence of two $M_{w}>6$ aftershocks within 24 hours after the mainshock. Using a simple approach similar to Reasenberg and Jones [1989], we forecast the number of aftershocks of magnitude $M_{w} \geq 6.3$ within 24 hours after the mainshock using $b=0.8$ and Omori-Utsu parameters mentioned above. Results shown in Fig. S1 indicate that there is only a probability of $0.3 \%$ of having at least two aftershocks of magnitude $M_{w} \geq 6.3$ shortly after the mainshock. However, this estimate depends on the assumed b-value. If we consider $b=0.7$ as for the Atacama sequence, the aforementioned probability increases to about $4 \%$.

\section{GPS data analysis}

Early 2019, in order to densify the CSN network [Báez et al., 2018], we installed 5 continuous GPS (cGPS) stations in the Atacama region. Three of them were collocated with broad-band seismometers (see section 2.1). Overall, we benefit from 12 cGPS stations lo- 
cated in the area of the sequence complemented by 5-6 stations further away for the reference (Fig. 1). In this study, we use both the stations positions obtained from 24-hours daily solutions throughout the whole duration of the sequence and the high rate $(1 \mathrm{~Hz}$, hereafter HRGPS) data that allow to decipher the successive displacements during the first day.

\subsection{4-hours daily solutions}

In addition to the data from the national Chilean network [Báez et al., 2018] and from the 5 additional stations, we include data of the Argentinian RAMSAC network [Piñón et al., 2018 ] and of the Brazilian RBMC network. We also include all the IGS stations available on the South American continent. This dataset is processed using the GAMIT/GLOBK software following the classical MIT methodology [Herring et al., 2010a,b]. In a second step, we produce daily time series by constraining continental stations to their well-known coordinates in the ITRF2014 [Altamimi et al., 2017] with the PYACS toolbox.

A specific difficulty needs to be addressed when several large earthquakes occur during the same day. If a single coordinate is calculated for the entire day, it will end up being anywhere between the pre- and post-earthquakes coordinate, depending on different parameters: when exactly the earthquakes occur during the day, which data segment (before, between and after the earthquakes) is the longest, and how the filter will handle data that does not fit the obtained average position of the day. In order to eliminate the pre-seismic observation (before 4:30 UTC) and to separate the two events in the data (see Fig. S2), we consider at which time the two main events occurred $\left(M_{w}=6.9\right.$ at 4:09 UTC and $M_{w}=6.4$ at 21:09 UTC) and the day of the earthquake was processed using only the observations acquired between 4:30 UTC and 21:00 UTC. Therefore, this day's position corresponds to an averaged position of the station after the first event $\left(M_{w}=6.9\right)$ and before the second event $\left(M_{w}=6.4\right)$. Note that the selected time window also allows us to exclude the $M_{w}=6.3$ aftershock. Because only 25 min separates this aftershock from the mainshock, the potential deformation generated by this aftershock is most likely impossible to differentiate from the mainshock, using daily GPS solutions.

Time series reveal significant displacements on at least 7 stations (Fig. 5). Steps between days 244 and 245 (resp. 245 and 246) correspond to the coseismic displacements generated by the first (resp. the second) event, both occurring during day 245 (September $\left.1^{\text {st }}\right)$. The typical curvature of the time series of the stations nearest the events during the 
days (possibly weeks) following the mainshock also reveals postseismic deformation. This deformation seems unusually large ( $\sim 100 \%$ in only a couple of days) at the nearest station (TTRL). The estimation of the coseismic displacement of the first event of $M_{w}=6.9$ at 04:09 (the mainshock) is obtained by differentiating between the position at midday 245 (between 4:30 and 21:00 UTC) and the position of the day before (244) (Fig. 6-A, vectors in light red). It includes part, but not all, of the post-seismic deformation occurring during the 15 hours time span between the mainshock and the large aftershock at 21:09, which is potentially a combination of rapid after-slip and a-seismic deformation, but also potential deformation due to the $M_{w}=6.3$ aftershock of 04:30. The estimation of the co-seismic displacement of the second event $\left(M_{w}=6.4\right)$ is obtained by difference between the position of the following day (246 - 02/09/2020) and the position of the day of the 2 earthquakes previously described (midday 245, between $4 \mathrm{~h} 30$ and 21:00 UTC). In a similar way, it also includes a combination of rapid after-slip and potential a-seismic deformation that might have occurred after both events (Fig. 6-B, vectors in light blue).

\subsection{High rate GPS observations}

High rate data are processed with Track software from MIT (T. Herring) which is a double-difference software, meaning that we compute the motion of a "rover" station relative to a "fixed" station. In this processing we use 5 "fixed" stations surrounding the area of interest (represented by black diamonds on Fig. 1): LSCH (La Serena) and LHOR (LosHornos) to the South; PAZU (Pan de Azucar) to the North; ALUM in Argentina and MRCG (Maricunga) to the East and North-East. We use the tropospheric zenital delays (ZTD) generated by the $24 \mathrm{~h}$ static solution (one delay estimated every 2 hours at every site) to constrain the tropospheric delay in the kinematic processing to the static value. For the three largest events, we generate motograms (high rate evolution of position with time, from the latin word "moto" for motion) of one hour spanning the events (see Fig. S5 for the mainshock at 4:09 UTC, Fig. S6 for the largest aftershock at 21h09 UTC and Fig. S7 for the smaller aftershock at 4:30 UTC). For all motograms, we built a sidereal filter by simply stacking the 1hour data segments, of 3 (or 6) days before the earthquake with a $4 \mathrm{~m} 7 \mathrm{~s}$ time delay everyday following Choi et al. [2004]. We then filter the co-seismic motogram, by simply subtracting this common mode to the original data. Then, the co-seismic jump is simply estimated as the offset between the 3-minutes data segment before and after the time of the earthquake (Fig. 6). Uncertainties are estimated visually from the motograms and range between 1 and 
$5 \mathrm{~mm}$ for the horizontal components and 5 and $10 \mathrm{~mm}$ for the vertical component. We are able to identify clear co-seismic jumps at most stations for the mainshock, small but discernable jumps at several stations for the largest aftershock, but nothing for the smaller aftershock of 4:30 UTC. This is an indication of the threshold detection of our current cGPS network : between magnitude 6.3 and 6.4 .

Comparing coseismic offsets extracted from both the daily solution and from the HRGPS solution offers some confidence. Although the HRGPS is associated with larger uncertainties $(5 \mathrm{~mm})$ than daily solutions $(1-2 \mathrm{~mm})$, both solutions appear very consistent and show very similar offset. Specifically, stations located more than $50 \mathrm{~km}$ from the epicenter compare very well (BING, MMOR, UDAT, TAMR, TOT5, TRST). However, for both events, nearfield stations (TTRL, BAR2, and LLCH) exhibit a smaller HRGPS coseismic offset (smaller by $50 \%$ ) than the daily solution one. This is very significant and indicates additional deformation is present immediately after the earthquake occurrence.

\section{Analysis of major earthquakes}

\subsection{Coseismic slip static inversions}

We built a fault geometry with triangular patches based on Slab2.0 [Hayes et al., 2018] between $26.5^{\circ} \mathrm{S}$ and $29^{\circ} \mathrm{S}$ and down to $60 \mathrm{~km}$ depth. We evaluated the slip distributions generated by the two largest earthquakes by inverting the coseismic displacements estimated from the HRGPS. We compute constrained least squares inversions using the CSI toolbox [Gombert et al., 2019]. For both models, we apply as little smoothing as possible and we forbid back slip in the thrust direction. We assume only one slip component which direction is fixed parallel to the plate convergence [convergence vector from Klein et al., 2018a]. Green functions are calculated at each node of the fault plane, assuming a homogeneous elastic half-space [Meade, 2007].

10 to 14 stations spanning the area were used in the inversion (Fig. 6). Resolution tests are fully described in the Supplemental material. They show that (1) a good recovery for $\sim 40 \mathrm{x} 40 \mathrm{~km}$ patterns is found between $15-55 \mathrm{~km}$ depth even with conservative noise budget for co-seismic offsets; (2) a very good (1-2 km) ability to locate the area of maximum slip; (3) peak-slip amounts are recovered within 10-30\% and magnitude by 0.1 ; (4) extent of slip might be smeared by a few $\mathrm{km}$. 
For the mainshock, we find a slip distribution spreading over a rather large surface of $80 \times 40 \mathrm{~km}^{2}$, between $27.5^{\circ} \mathrm{S}$ and $28.5^{\circ} \mathrm{S}$. This surface seems too large for a $M_{w} 6.9$ earthquake, but the bulk of the slip is concentrated in a much smaller area of only about $25 \times 20 \mathrm{~km}^{2}$ (Fig. 7-A). There is a trade-off between the quantity of slip and the size of the rupture zone. We test several models in which we concentrate larger slip amount in a narrower zone (for ex. within the region currently yielding more than $60 \mathrm{~mm}$, or more than $80 \mathrm{~mm}$ of slip, see Fig. S8). Southward offsets can be reproduced by a larger amount of slip in the north (see Fig.S8-B). But reducing the rupture zone to $\sim 30$ x $30 \mathrm{~km}^{2}$ leads to significantly larger residuals at closest stations (BAR2 and TTRL, Fig. S8-C). Therefore, the extension of the rupture zone to the north is required by the observations at more than $50 \mathrm{~km}$, yielding significant westward coseismic offsets which are not converging toward a pin point. The best fit model includes a narrow strip of slip, elongated below the coastline south of the high slip area. This feature depicts only several $\mathrm{cm}$ of slip and is requested only by millimetric variations at a few stations. It may be beyond the resolution of our data and modelling. The deep extension of slip, reaching $40 \mathrm{~km}$ down, observed at $28^{\circ} \mathrm{S}$ seems required both by the large coseismic displacement measured at station TOT5 located some $75 \mathrm{~km}$ away from the epicenter, and by the coseismic uplift measured at BAR2 and LLCH. Although vertical data do not appear essential since an inversion considering only the horizontal coseismic displacements produces similar slip pattern. We tested models with pure dip slip direction perpendicular to the trench, and models with two slip directions, but neither provides satisfying results (see supporting information for more details). We estimate a seismic potency of $4.14 \cdot 10^{8} \mathrm{~m} . \mathrm{m}^{2}$, which corresponds to a moment of $2.01 \cdot 10^{19}$ N.m $\left(M_{w}=6.8\right)$ using a shear modulus of 4.9 $\cdot 10^{10} \mathrm{~Pa}$ (which is the value used for the $\mathrm{W}$-phase). The geodetic moment appears slightly smaller than the seismic moment re-estimated at long-period using the W-phase but still lies within the error bar. Considering the size of this event, we made the approximation of a homogeneous half-space for all our inversions, which could account for part of the difference.

For the largest aftershock, because it generates smaller displacements than the mainshock at many stations, we dispose of less well determined co-seismic vectors. In particular we do not use any vertical displacement in the inversion of the aftershock slip distribution. Also, considering that we have very few observations, we decreased the uncertainties of nonzero vectors to $1 \mathrm{~mm}$, in order to strongly encourage the model to fit these. We find a circular slip distribution, significantly smaller with about 30 x $30 \mathrm{~km}$ overall (only 10 x $10 \mathrm{~km}$ for the bulk of the slip), with a peak slip at $95 \mathrm{~mm}$ (Fig. 7-B). For this event as well, the 
geodetic moment also appears slightly larger than the seismologic one, with $6.04 \cdot 10^{18} \mathrm{~N} . \mathrm{m}$ $\left(M_{w}=6.5\right.$, corresponding to a seismic potency of $\left.1.24 \cdot 10^{8} \mathrm{~m} \cdot \mathrm{m}^{2}\right)$. Finally, the epicenter of the mainshock is located on the updip-western edge of the rupture zone, suggesting a downdip-bilateral propagation. The aftershock slip distribution is located updip the mainshock rupture zone and shows a striking complementary (Fig. 7-C). The aftershock lies in the hole left by the bean-shaped mainshock. Together they homogenise the slip over a larger and rounder area.

\subsection{Dynamic inversions}

We used seismic waveforms from strong motion stations deployed in the area (Fig. 1) to estimate the dynamic properties of the coseismic rupture. The low-frequency source properties (e.g., average slip and stress drop) of the largest event were estimated using an elliptical patch approach (e.g., [Ruiz and Madariaga, 2011; Herrera et al., 2017]). In this model, the rupture nucleates within a circular area and then propagates through a larger elliptical area. This rupture process is controlled by the friction law proposed by Ida [1972]. Hence, in addition to the geometric parameters defining the circle and the ellipse, this dynamic model also includes the stress drop $\left(T_{e}\right)$, the yield stress $\left(T_{\mu}\right)$, and the slip-weakening distance $\left(D_{c}\right)$. We used strong-motion records integrated to displacement and band-pass filtered in low frequency (0.02-0.2 Hz for the mainshock). The AXITRA code [Bouchon, 1981; Coutant, 1989] was used to simulate the source-to-receiver wave propagation via an appropriate 1-D velocity model for the area, which was extracted from [Potin et al., 2019]. The inversion of the dynamic model was performed using the Neighborhood Algorithm [Sambridge, 1999], which finds the model that best fits the observed waveform data. The misfit between observed and modeled waveforms was calculated using an L2 norm.

The best solution for the mainshock converged toward an elliptical rupture of $24.4 \mathrm{~km}$ by $26 \mathrm{~km}$ (Fig. 8), with a minimum misfit of 0.24 (Figs. 8 and S11), a maximum slip of $1.1 \mathrm{~m}$ and a $M_{w}=6.7$, which is similar to the solution obtained from HRGPS (Fig. 7). Also, the associated dynamic parameters are $T_{e}=5.3 \mathrm{MPa}, T_{\mu}=5.59 \mathrm{MPa}$, and $D_{c}=0.72 \mathrm{~m}$. These dynamic parameters are similar to those obtained for inter plate events along Chilean subduction [Ruiz et al., 2017; Otarola et al., 2021] and the stress drop parameters are in the average of thrust earthquakes occurring on a subduction interface [Kanamori and Anderson, 1975]. 


\section{Interplay between seismic and aseismic slip}

\subsection{Static inversion of afterslip on the day of the mainshock}

On one hand, we compute the total co-seismic motion due to both events, both quantified by daily cGPS between the 30/08/2020 and the 02/09/2020 (shown in light red on Fig. 9-A). This calculation includes both events and the total amount of aseismic slip that occurred over the two days. On the other hand, we compute the total displacements measured by HRGPS (shown by dark red arrows on Fig. 9-A). Considering that the HRGPS allows to extract the pure co-seismic motion over a couple of minutes around the earthquakes, the difference between the total daily cGPS co-seismic estimates and the total HRGPS estimates (Fig. 9-B) should highlight the amount of early afterslip during the day of the earthquakes. Indeed, this difference shows a significant westward motion at TTRL and BAR2, similar to the post-seismic motion observed over the following days (Fig. 9-C).

Using the same methodology and parameters as previously (section 4.1), we compute static inversions of the different displacements fields. Unsurprisingly, the slip distribution inferred from the total daily cGPS displacements (Fig. 9-Ai, noted in following Ai) shows significantly more slip than the slip distribution inferred from the total HRGPS displacements (Fig. 9-Aii, noted in following Aii). In particular the peak slip of (Ai) reaches $17 \mathrm{~cm}$ compared to only $10 \mathrm{~cm}$ for (Aii). But both distributions show very similar patterns over a somehow circular area extending from $27.4^{\circ} \mathrm{S}$ to $28.5^{\circ} \mathrm{S}$. The distribution of early postseismic shows slip occurring on a significantly smaller, narrow peanut-shape area elongated along a roughly NS direction (Fig. 9-B). Part of this slip could be coseismic slip due the $M_{w}=6.3$ aftershock which occurred at 4:30 UTC and that we were not able to extract from HRGPS. Small amount of slip observed at greater depth is most likely unresolved.

\subsection{Time-dependent inversion of the postseismic deformation}

Significant displacements are observed on the cGPS time series during a 22-days period, between the $2^{\text {nd }}$ and the $24^{\text {th }}$ of September. In order to quantify the slip evolution after the second large aftershock, we perform a kinematic inversion of the cGPS times series. We invert for slip on the subduction interface (following Rolandone et al. [2018] and Bletery and Nocquet [2020]). We find that the best fit to the time series is obtained with a smoothing parameter $\sigma=20 \mathrm{~mm} \cdot \sqrt{\text { day }}$ and a correlation distance between subfaults of $D_{\text {corr }}=35 \mathrm{~km}$. The total slip after 22 days is equivalent to $M_{w}=6.8$. Overall, it spreads over roughly the 
same area as the area ruptured by the mainshock and its largest aftershock, between $27.5^{\circ} \mathrm{S}$ and $28^{\circ} \mathrm{S}$ (Fig. 9-C). A static inversion of the cumulative postseismic displacement (following the same methodology as the coseismic static inversions) over the same period yields a very similar same pattern (Fig. S12). Regarding its spatio-temporal evolution, the postseismic slip begins offshore and starts developing onshore and deeper after 6 days (Fig. 9-C1 \& 9-C2). At a later stage, on the ninth day, a dissociated smaller patch begins more to the North, between $27^{\circ} \mathrm{S}$ and $27.5^{\circ} \mathrm{S}$ (Fig. 9-C3). It is deeper - at a depth of approximately 35 to $55 \mathrm{~km}$ - and localised in the updip vicinity of the 2014 slow slip event [Klein et al., 2018b]. The northward migration of post-seismic slip is associated with a northward rotation of postseismic vectors wrt. co-seismic vectors at several stations near the epicenter area (BAR2, LLCH, TTRL) and the development of Westward vectors North of the epicenter area (BING, MMOR, UDAT). The source time function associated to this inversion shows a quasi-steady decrease in the slip's intensity. Then, negligible slip is found to occur after approximately 18 days. A movie of the postseismic slip evolution is provided in the supporting information.

\section{Discussion and Conclusions}

\subsection{General agreement and small discrepancies}

Concerning the mainshock, the different types of modelling presented here are in good agreement, with some discrepancies regarding the magnitudes, the size of slip distributions and the peak slip. The dynamic model yields a smaller magnitude $\left(M_{w}=6.7\right)$ than the one inferred from the W-phase $\left(M_{w}=6.9\right)$. This is common and due to the simple elliptical geometry used for the dynamic inversion, which can therefore not fully capture the correct slip distribution and concentrate the solution. GPS constrained slip models yield a magnitude of 6.8 , slightly smaller than the $\mathrm{W}$-phase magnitude, but the difference is within the error bar (cf section 2.2 and table S1, same observation for the difference in magnitude of the largest aftershock between the static inversion and the W-phase analysis). Slip models inferred from GPS show a quite larger rupture zone, which could have several origins. First, it could be an artefact imposed by wrongly detected small displacements at stations located farther away from the epicenter, although this should mostly be taken into account by the uncertainties. Second, the geodetic models might be contaminated by inaccuracies in the Earth model as we assume an homogeneous half-space and neglect topography [e.g., Duputel et al., 2014; Langer et al., 2020]. Finally, the model resolution is limited by the number of observations, resulting in a trade-off between the amount of slip and the size of the rupture. Eventually, 
from both analyzes, we are confident that the greatest slip is well concentrated in an area of $30 \times 30 \mathrm{~km}^{2}$, associated with the rupture of a single asperity. The HRGPS inversion shows a more extended rupture area, the lesser slip regions probably being at the resolution limit of our data.

\subsection{Relation with Coupling on the interface}

We compare the two slip distributions with the coupling distribution proposed in the region by Klein et al. [2018a] (Fig. 10. The whole September sequence takes place in between the highly coupled Atacama segment (South of $28^{\circ} \mathrm{S}$ ), and the Chañaral segment (North of $27^{\circ} \mathrm{S}$ ). There, in the so-called Baranquilla inter-segment, we observe a narrow strip highly coupled connecting the 2 segments with significantly lower coupling on both the shallower and deeper part of the interface. We find that most of the slip due to the 01/09/2020 mainshock (dark blue contour) occurred downdip of its epicenter (dark blue dot), mostly overlapping the narrow strip of higher coupling. The largest aftershock at 21:09 UTC (light blue contour) shows a striking complementarity with the mainshock, occurring updip and extending in the low coupled region (Fig. 10). Early afterslip that occurs during the 17 hours between the mainshock and the largest aftershock (Fig. 9-B), is located mostly between the rupture zones of the two earthquakes, in a peanut-like shape (Fig. 10). Part of the obtained slip could be coseismic due to the 4:30 UTC $M_{w}=6.3$ aftershock, and part indeed due to aseismic slip.

\subsection{Interplay of seismic and aseismic slip in an area of heterogeneous coupling}

We showed that the probability of having at least two aftershocks of magnitude $M_{w}>$ 6 within 24 hours is quite low. This leads us to question whether it is a simple mainshockaftershock sequence or a seismic swarm, which is commonly defined as an increase of seismicity rate without a clear mainshock earthquake [Holtkamp et al., 2011]. It could also mean that there is room for other processes that could have triggered these earthquakes so shortly after the mainshock.

During the first 17 hours, seismicity spread updip the mainshock epicenter and outside its rupture zone, into what later became the largest aftershock rupture zone, (Fig. 7-C). The asymmetry observed between the updip and downdip propagations of seismicity over the first $72 \mathrm{~h}$ (Fig. 3-C) is most likely driven by a specific source. Incidentally, the quantity 
of aseismic slip occurring directly after the mainshock, and over the following 20 days, is abnormally high. There is some overlap between the afterslip distribution, and the the coseismic slip distributions of the mainshock and the largest aftershock (Fig. 10). But the bulk of the distributions are disconnected and the overlap lies within the regions of lesser slip. We suggest that slow slip could be responsible for increasing shear stress at the front of the slip zone, propagating updip at approximately $0.7 \mathrm{~km} /$ hour ([which is within the range of slow slip propagation speeds observed elsewhere, Gao et al., 2012] - Fig. 3-C), until surrounding a locked asperity which eventually triggered the $M_{w}=6.4$ aftershock, 17 hours after the mainshock. Such a relation between seismicity at the front of the slip has been proposed in various context, during the interseismic phase but also during SSE, associated or not with non-volcanic tremors [Bartlow et al., 2011, 2014; Vaca et al., 2018; Bletery and Nocquet, 2020], and is consistent with numerical models of seismicity driven by slow slip [e.g. Ariyoshi et al., 2012; Yingdi and Ampuero, 2017; Wynants-Morel et al., 2020]

The equivalent moment released over a period of 22 days, following the mainshock, reaches more than $80 \%$ of the coseismic moment, spreading in a much broader region than the coseismic rupture zone where the coupling is lower, as well as in a broader region than the aftershocks area. Usually, postseismic deformation reaches around $25 \%$ of the co-seismic deformation after a month. However, several cases have been documented where moderate size earthquakes are followed by abnormally large afterslip in Japan [Yagi et al., 2001; Suito et al., 2011] and northern Peru where moment released through aseismic slip during a sequence was several time larger ( 3 to 14 ) than the moment released through earthquakes [Villegas Lanza et al., 2015]. For the latter, it has been suggested that additional processes - i.e. not only an earthquake but also, for example, one or several slow slip events - were involved to explain such a large amount of afterslip. A similar hypothesis was proposed to explain the abnormally rapid and large early afterslip following the $2016 M_{w} 7.8$ Ecuador earthquake [Rolandone et al., 2018]. Complex sequence with large afterslip occurring very close a the recurrent SSE patch was also observed in Mexico [Radiguet et al., 2016]. The Atacama region seems propitious to slow slip events, while such an event was observed in the region in 2014 [Klein et al., 2018b]. Here, overall, we estimated from the geodetic models that the sequence released a total moment of $4.94 \cdot 10^{19} \mathrm{~N} \cdot \mathrm{m}\left(M_{w}=7.1\right)$, with close to $60 \%$ through earthquakes and $40 \%$ through aseismic slip. Slip occurred spread over an area of $\sim 100 \times 100 \mathrm{~km}^{2}$, much larger than expected for $\mathrm{M}<7$ earthquakes, also highlighting the role of aseismic slip during the sequence. Postseismic slip migrates to greater depth 6 days after 
the mainshock, reaching eventually the 2014 slow slip area. Therefore, the Baranquilla LCZ seems prone for aseismic processes, potentially recurrent at depth as observed in the past, and favors large postseismic slip.

\subsection{Considerations on seismic hazard in the area}

Considering the historical seismicity in the region, i.e. the $M_{w} \geqslant 8.5$ mega-earthquakes of 1819 and 1922, and the high coupling imaged in the Atacama and Chañaral segments, we previously suggested that a joint rupture of these two segments was highly plausible in the future [Klein et al., 2018b]. Both segments have indeed accumulated enough deformation since 1922 to generate a $M_{w} \geqslant 8$ earthquake [Klein et al., 2018a]. What is the impact of this sequence regarding scenarios for future megathrust ruptures in the region? Different scenarios seem plausible. On one hand, the whole September 2020 sequence is likely to have increased the stress at the edges of the highly locked Atacama and Chañaral segments, promoting future rupture(s) there. In particular the whole sequence occurred very near the northern edge of the Atacama segment. Could this initiate the destabilization of this highly locked patch and trigger a rupture of this segment already? And would a rupture of the Atacama segment trigger in turn the rupture of the Chanaral segment, initiating a 1819 or 1922 like megathrust earthquake ? On the other hand, this same sequence may have released a significant amount of stress in the Baranquilla LCZ, which could in turn decrease the potential for a joint rupture of the Atacama and Chañaral segments by reinforcing its ability to act as a barrier for megathrust rupture propagation. In this scenario, Atacama and Chañaral segments could rupture independently, at different times and with smaller earthquakes than in 1819 and 1922. It is difficult to decipher between these scenarios, but the occurrence of a seismic sequence between two highly locked patches identified to be responsible for devastating earthquakes 100 and 200 years ago is a clear sign that this region should be monitored closely in the next future.

\section{Acknowledgments}

We would like to warmly thank all CSN staff, for their precious help for the fieldwork. We also are thankful to the CSN, IRIS and IPOC for providing the data used in this study, as well as to the Institut National des Sciences de l'Univers (INSU-CNRS) and the Réseau Sismologique \& Géodésique Français (RESIF, as part of the "Investissements d'Avenir" program, ANR-11-EQPX-0040, and the French Ministry of Ecology, Sustainable Develop- 
ment and Energy) for providing the geodetic instruments for campaigns and 3 broadband seismometers. Part of the computations presented in this paper were performed using the GRICAD infrastructure (https://gricad.univ-grenoble-alpes.fr), which is supported by Grenoble research communities. Finally, we would like to thank our reviewer for the constructive comments which helped us improving our manuscript.

Fundings: This work was supported by the Agence Nationale de la Recherche (projects ANR-19-CE31-0003), the CNRS-INSU Tellus program and the European Research Council (ERC) under the European Union's Horizon 2020 research and innovation program (grant agreement $\mathrm{n}^{\circ}$ : 805256). SR was supported by Fondecyt project ( $\mathrm{N}^{\circ} 1200779$, ANID, Chile). JCB was supported by FONDECYT1200779 and ANID PIA ACT192169

Figures have been made using Generic Mapping Tools GMT [Wessel et al., 2013] using topography from ETOPO5. Python toolboxes used: PYACS+ PYEQ (https://github. com/JMNocquet/pyacs36, CSI (http://www.geologie.ens.fr/ jolivet/csi) and Pyrocko (https://pyrocko.org/)

Data availability: Seismic data collected are available through the Incorporated Research Institutions for Seismology (IRIS) Data Management Center. The results of the Wphase analysis are available on the Supporting information. The relocated catalog will be made available at final publication.

The coseismic offset tables extracted from daily and HRGPS presented in the study are in the supporting information. Position time series of the sequence can be made available upon request.

\section{References}

Aki, K. (1965), Maximum likelihood estimate of $\mathrm{b}$ in the formula $\log \mathrm{N}=\mathrm{a}-\mathrm{bM}$ and its confidence limits, Bull. Earthq. Res. Inst., Tokyo Univ., 43, 237-239.

Altamimi, Z., L. Métivier, P. Rebischung, H. Rouby, and X. Collilieux (2017), Itrf2014 plate motion model, Geophysical Journal International, 209(3), 1906-1912.

Ariyoshi, K., T. Matsuzawa, J.-P. Ampuero, R. Nakata, T. Hori, Y. Kaneda, R. Hino, and A. Hasegawa (2012), Migration process of very low-frequency events based on a chainreaction model and its application to the detection of preseismic slip for megathrust earthquakes, Earth, planets and space, 64(8), 693-702. 
Báez, J., F. Leyton, C. Troncoso, F. del Campo, M. Bevis, C. Vigny, M. Moreno, M. Simons, E. Kendrick, H. Parra, et al. (2018), The Chilean GNSS network: Current status and progress toward early warning applications, Seismological Research Letters.

Barrientos, S. (2018), The seismic network of chile, Seismological Research Letters, 89(2A), $467-474$.

Bartlow, N. M., S. Miyazaki, A. M. Bradley, and P. Segall (2011), Space-time correlation of slip and tremor during the 2009 cascadia slow slip event, Geophysical Research Letters, $38(18)$.

Bartlow, N. M., L. M. Wallace, R. J. Beavan, S. Bannister, and P. Segall (2014), Timedependent modeling of slow slip events and associated seismicity and tremor at the hikurangi subduction zone, new zealand, Journal of Geophysical Research: Solid Earth, 119(1), 734-753.

Beck, S., S. Barrientos, E. Kausel, and M. Reyes (1998), Source characteristics of historic earthquakes along the central Chile subduction zone, Journal of South American Earth Sciences, 11, 115-129.

Bletery, Q., and J.-M. Nocquet (2020), Slip bursts during coalescence of slow slip events in cascadia, Nature communications, 11(1), 1-6.

Bloch, W., J. Kummerow, P. Salazar, P. Wigger, and S. A. Shapiro (2014), High-resolution image of the North Chilean subduction zone: seismicity, reflectivity and fluids, Geophysical Journal International, 197(3), 1744-1749.

Bloch, W., T. John, J. Kummerow, P. Salazar, O. S. Krüger, and S. A. Shapiro (2018), Watching dehydration: Seismic indication for transient fluid pathways in the oceanic mantle of the subducting Nazca slab, Geochemistry, Geophysics, Geosystems, 19(9), 3189-3207, doi:10.1029/2018GC007703.

Bouchon, M. (1981), A simple method to calculate Green's functions for elastic layered media, Bulletin of the Seismological Society of America, 71(4), 959-971.

Choi, K., A. Bilich, K. M. Larson, and P. Axelrad (2004), Modified sidereal filtering: Implications for high-rate gps positioning, Geophysical research letters, 31(22).

Comte, D., and G. Suarez (1994), An inverted double seismic zone in Chile: Evidence of phase transformation in the subducted slab, Science, 263(5144), 212-215.

Comte, D., M. Pardo, L. Dorbath, C. Dorbath, H. Haessler, L. Rivera, A. Cisternas, and L. Ponce (1992), Crustal seismicity and subduction morphology around antofagasta, chile: preliminary results from a microearthquake survey, Tectonophysics, 205(1-3), 13-22. 
Comte, D., H. Haessler, L. Dorbath, M. Pardo, T. Monfret, A. Lavenu, B. Pontoise, and Y. Hello (2002), Seismicity and stress distribution in the copiapo, northern Chile subduction zone using combined on- and off-shore seismic observations, Physics of the Earth and Planetary Interiors, 132(1-3), 197 - 217, doi:http://dx.doi.org/10.1016/S0031-9201(02) 00052-3, subduction Zone Structure and Megathrust Earthquakes.

Coutant, O. (1989), Programme de simulation numerique AXITRA, Rapport LGIT.

Duputel, Z., L. Rivera, H. Kanamori, and G. Hayes (2012), W phase source inversion for moderate to large earthquakes (1990-2010), Geophysical Journal International, 189(2), 1125-1147, doi:10.1111/j.1365-246X.2012.05419.x.

Duputel, Z., P. S. Agram, M. Simons, S. E. Minson, and J. L. Beck (2014), Accounting for prediction uncertainty when inferring subsurface fault slip, Geophys. J. Int., 197(1), 464482.

Efron, B., and R. J. Tibshirani (1993), An introduction to the Bootstrap, Chapman \& HALL/CRC.

Gao, H., D. A. Schmidt, and R. J. Weldon (2012), Scaling relationships of source parameters for slow slip events, Bulletin of the Seismological Society of America, 102(1), 352-360.

Gombert, B., Z. Duputel, E. Shabani, L. Rivera, R. Jolivet, and J. Hollingsworth (2019), Impulsive source of the $2017 \mathrm{mw}=7.3$ ezgeleh, iran, earthquake, Geophysical research letters, 46(10), 5207-5216.

Hayes, G. P., G. L. Moore, D. E. Portner, M. Hearne, H. Flamme, M. Furtney, and G. M. Smoczyk (2018), Slab2, a comprehensive subduction zone geometry model, Science, $362(6410), 58-61$.

Herrera, C., S. Ruiz, R. Madariaga, and P. Poli (2017), Dynamic inversion of the 2015 Jujuy earthquake and similarity with other intraslab events, Geophysical Journal International, 209(2), 866-875.

Herring, T., R. King, and S. C. McClusky (2010a), GAMIT : GPS Analysis at MIT, release 10.4 .

Herring, T., R. King, and S. C. McClusky (2010b), GLOBK : Global Kalman filter VLBI and GPS analysis program release 10.4 .

Holtkamp, S. G., M. E. Pritchard, and R. B. Lohman (2011), Earthquake swarms in South America, Geophysical Journal International, 187(1), 128-146, doi:10.1111/j.1365-246X. 2011.05137.x. 
Ida, Y. (1972), Cohesive force across the tip of a longitudinal-shear crack and Griffith's specific surface energy, Journal of Geophysical Research, 77(20), 3796-3805.

Kanamori, H., and D. L. Anderson (1975), Theoretical basis of some empirical relations in seismology, Bulletin of the seismological society of America, 65(5), 1073-1095.

Kanamori, H., L. Rivera, L. Ye, T. Lay, S. Murotani, and K. Tsumura (2019), New constraints on the 1922 atacama, chile, earthquake from historical seismograms, Geophysical Journal International, 219(1), 645-661.

Klein, E., M. Métois, and V. C. D. A. Meneses, G. (2018a), Bridging the gap between North and Central Chile : insight from new GPS data on coupling complexities and the Andean sliver motion, Geophysical Journal International, 213(3), 1924 - 1933.

Klein, E., Z. Duputel, D. Zigone, C. Vigny, J.-P. Boy, C. Doubre, and G. Meneses (2018b), Deep transient slow slip detected by survey gps in the region of atacama, chile, Geophysical research letters, 45(22), 12-263.

Langer, L., T. Ragon, A. Sladen, and J. Tromp (2020), Impact of topography on earthquake static slip estimates, Tectonophysics, 791, 228,566.

Leyton, F., A. Leopold, G. Hurtado, C. Pastén, S. Ruiz, G. Montalva, and E. Saez (2018), Geophysical characterization of the chilean seismological stations: First results, Seismological Research Letters, 89(2A), 519-525.

Lomnitz, C. (2004), Major earthquakes of Chile: A historical survey, 1535-1960, Seismological Research Letters, 75, 368-378, doi:10.1785/gssrl.75.3.368.

Meade, B. J. (2007), Algorithms for the calculation of exact displacements, strains, and stresses for triangular dislocation elements in a uniform elastic half space, Computers \& Geosciences, 33(8), 1064-1075.

Métois, M., A. Socquet, C. Vigny, D. Carrizo, S. Peyrat, A. Delorme, E. Maureira, M.-C. Valderas-Bermejo, and I. Ortega (2013), Revisiting the north Chile seismic gap segmentation using GPS-derived interseismic coupling, Geophysical Journal International, 194(3), 1283-1294, doi:10.1093/gji/ggt183.

Métois, M., C. Vigny, and A. Socquet (2016), Interseismic coupling, megathrust earthquakes and seismic swarms along the Chilean subduction zone (38-18 ${ }^{\circ}$ S), Pure and Applied Geophysics, 173(5), 1431-1449.

Omori, F. (1894), On the Aftershocks of Earthquakes, Journal of the College of Science, Imperial University of Tokyo, 7, 111-200. 
Otarola, C., S. Ruiz, C. Herrera, R. Madariaga, and C. Siegel (2021), Dynamic rupture of subduction earthquakes located near the trench, Earth and Planetary Science Letters, 562, 116,842 .

Pacheco, J. F., and L. R. Sykes (1992), Seismic moment catalog of large shallow earthquakes, 1900 to 1989, Bulletin of the Seismological Society of America, 82(3), 1306-1349.

Pastén-Araya, F., P. Salazar, S. Ruiz, E. Rivera, B. Potin, A. Maksymowicz, E. Torres, J. Villarroel, E. Cruz, J. Valenzuela, D. Jaldín, G. González, W. Bloch, P. Wigger, and S. A. Shapiro (2018), Fluids Along the Plate Interface Influencing the Frictional Regime of the Chilean Subduction Zone, Northern Chile, Geophysical Research Letters, 45(19), 10,37810,388, doi:10.1029/2018GL079283.

Pastén-Araya, F., B. Potin, S. Ruiz, L. Zerbst, F. Aden-Antoniów, K. Azúa, E. Rivera, A. Rietbrock, P. Salazar, and A. Fuenzalida (2021), Seismicity in the upper plate of the Northern Chilean offshore forearc: Evidence of splay fault South of the Mejillones peninsula., Tectonophysics, accepted.

Piñón, D. A., D. D. Gómez, R. Smalley Jr, S. R. Cimbaro, E. A. Lauría, and M. G. Bevis (2018), The history, state, and future of the Argentine continuous satellite monitoring network and its contributions to geodesy in Latin America, Seismological Research Letters, $89(2 \mathrm{~A}), 475-482$.

Potin, B., S. Barrientos, B. Valette, and S. Ruiz (2019), Tomography of Chile, in 8th International Symposium on Andean Geodynamics (ISAG).

Radiguet, M., H. Perfettini, N. Cotte, A. Gualandi, B. Valette, V. Kostoglodov, T. Lhomme, A. Walpersdorf, E. C. Cano, and M. Campillo (2016), Triggering of the $2014 \mathrm{Mw} 7.3 \mathrm{~Pa}-$ panoa earthquake by a slow slip event in Guerrero, Mexico, Nature Geoscience, 9(11), 829.

Reasenberg, P. A., and L. M. Jones (1989), Earthquake hazard after a mainshock in california, Science, 243(4895), 1173-1176.

Rolandone, F., J.-M. Nocquet, P. A. Mothes, P. Jarrin, M. Vallée, N. Cubas, S. Hernandez, M. Plain, S. Vaca, and Y. Font (2018), Areas prone to slow slip events impede earthquake rupture propagation and promote afterslip, Science Advances, 4(1), eaao6596.

Ruiz, S., and R. Madariaga (2011), Determination of the friction law parameters of the mw 6.7 michilla earthquake in northern chile by dynamic inversion, Geophysical Research Letters, 38(9). 
Ruiz, S., and R. Madariaga (2018), Historical and recent large megathrust earthquakes in chile, Tectonophysics, pp. -, doi:https://doi.org/10.1016/j.tecto.2018.01.015.

Ruiz, S., F. Aden-Antoniow, J. Baez, C. Otarola, B. Potin, F. Campo, P. Poli, C. Flores, C. Satriano, F. Leyton, et al. (2017), Nucleation phase and dynamic inversion of the Mw 6.9 Valparaíso 2017 earthquake in Central Chile, Geophysical Research Letters, 44(20).

Sambridge, M. (1999), Geophysical inversion with a neighbourhood algorithm-I. Searching a parameter space, Geophysical journal international, 138(2), 479-494.

Sippl, C., B. Shurr, G. Asch, and J. Kummerow (2018), Seismicity structure of the northern Chile forearc from $>100,000$ double-difference relocated hypocenters, Journal of Geophysical Research: Solid Earth, 123(5), 4063-4087.

Soloviev, S., and C. Go (1976), Catalog of tsunamis on the western coast of the pacific ocean, nauka, urss (in russian).

Suito, H., T. Nishimura, M. Tobita, T. Imakiire, and S. Ozawa (2011), Interplate fault slip along the japan trench before the occurrence of the 2011 off the pacific coast of tohoku earthquake as inferred from gps data, Earth, planets and space, 63(7), 19.

Utsu, T. (1957), Magnitude of Earthquakes and Occurrence of their Aftershocks, Zisin (J. Seismol. Soc. Jap.), 10, 35-45, doi:10.4294/jpe1952.43.1.

Vaca, S., M. Vallée, J.-M. Nocquet, J. Battaglia, and M. Régnier (2018), Recurrent slow slip events as a barrier to the northward rupture propagation of the 2016 pedernales earthquake (central ecuador), Tectonophysics, 724, 80-92.

Villegas Lanza, J., J. Nocquet, F. Rolandone, M. Vallee, H. Tavera, F. Bondoux, T. Tran, X. Martin, and M. Chlieh (2015), A slow slip and seismic swarm sequence in a weakly coupled subduction zone in northern peru, AGUFM, 2015, S31A-2735.

Wessel, P., W. H. F. Smith, R. Scharroo, J. Luis, and F. Wobbe (2013), Generic Mapping Tools: Improved version released, Eos, Transactions American Geophysical Union, 94(45), 409-410, doi:10.1002/2013EO450001.

Willis, B. (1929), Studies in Comparative Seismology: Earthquake Conditions in Chile, 382, Carnegie Institution of Washington.

Wynants-Morel, N., F. Cappa, L. De Barros, and J.-P. Ampuero (2020), Stress perturbation from aseismic slip drives the seismic front during fluid injection in a permeable fault, Journal of Geophysical Research: Solid Earth, 125(7), e2019JB019,179.

Yagi, Y., M. Kikuchi, and T. Sagiya (2001), Co-seismic slip, post-seismic slip, and aftershocks associated with two large earthquakes in 1996 in hyuga-nada, japan, Earth, planets 
${ }_{676} \quad$ and space, 53(8), 793-803.

677 Yingdi, L., and J.-P. Ampuero (2017), Preprint: Tremor migration patterns and the collective 678 behavior of deep asperities mediated by creep. 


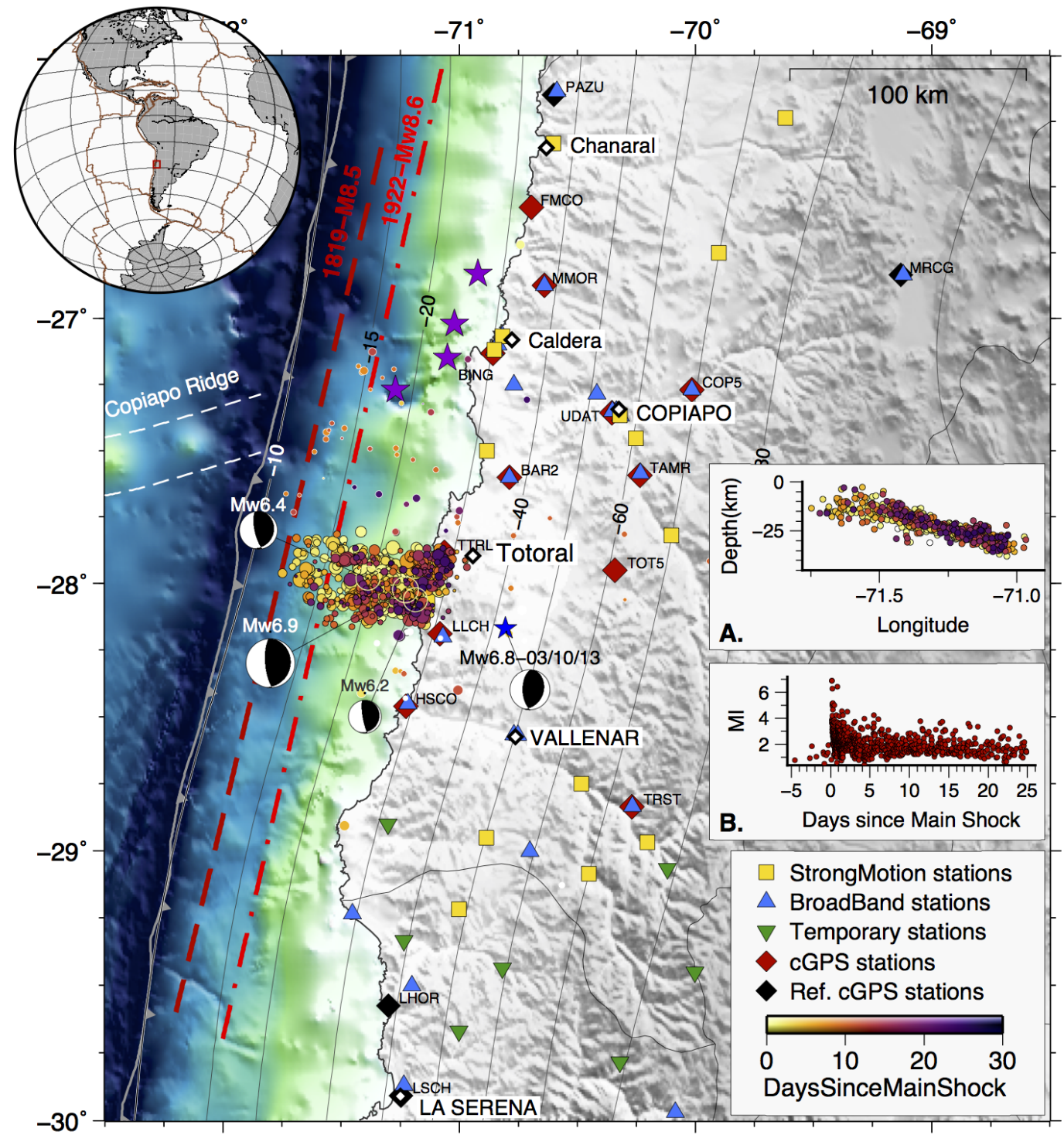

Figure 1. Overall context of the sequence of September 2020 in the Atacama region of Chile. The relocated earthquakes catalog is plotted as a function of time since the mainshock (in days since the mainshock). Events represented with white contours were relocated outside of the core sequence. Mechanisms and $M_{w}$ of the 3 largest events are the re-estimated one. The different observation networks used in this study are represented. A. Cross section of the relocated catalog of the core sequence, as function of depth, with the same color scale function of time. B. Local magnitudes $M_{l}$ of the relocated catalog of the core sequence as function of time. Violet stars show swarms locations [Holtkamp et al., 2011]. Slab isodepth from Hayes et al. [2018]. The dashed red lines illustrates the approximate length 1819 and 1922 earthquakes rupture zones. 


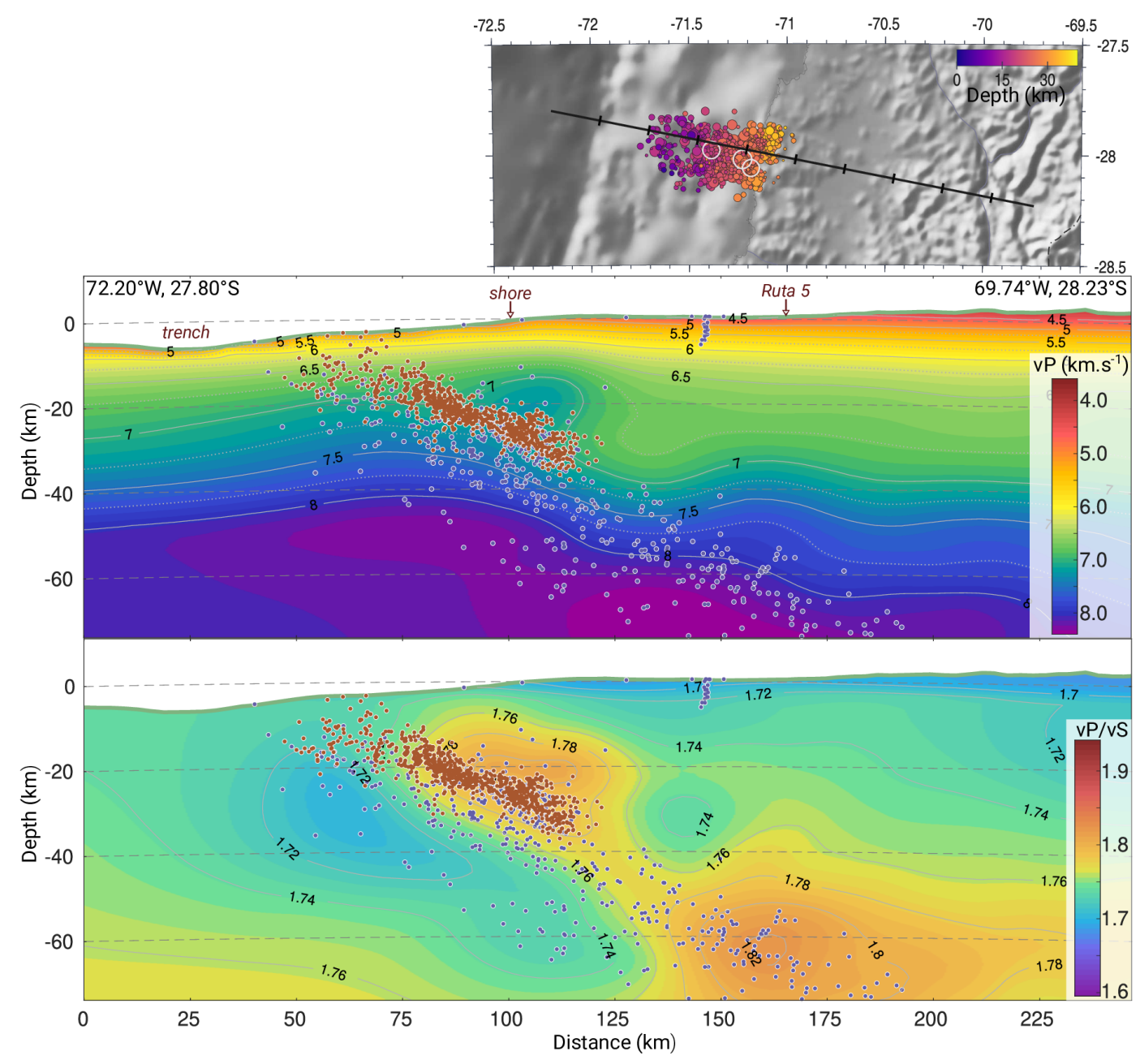

Figure 2. Vertical cross-section of tomography model for both P-wave velocity and $\mathrm{V}_{P} / \mathrm{V}_{S}$ velocity ratio.

Cross-section oriented perpendicular to the trench, across the sequence. Blue dots represent background seismicity in a $50 \mathrm{~km}$ range from the cross-section (CSN catalog, $2013-07 / 2020)$. Red dots represent the seismic sequence between August $25^{\text {th }}$ and September $25^{\text {th }}$ included. All earthquakes were relocated in the local 3D tomography model presented. Seismicity of the sequence spreads along subduction contact between the trench and about $40 \mathrm{~km}$ at depth. 

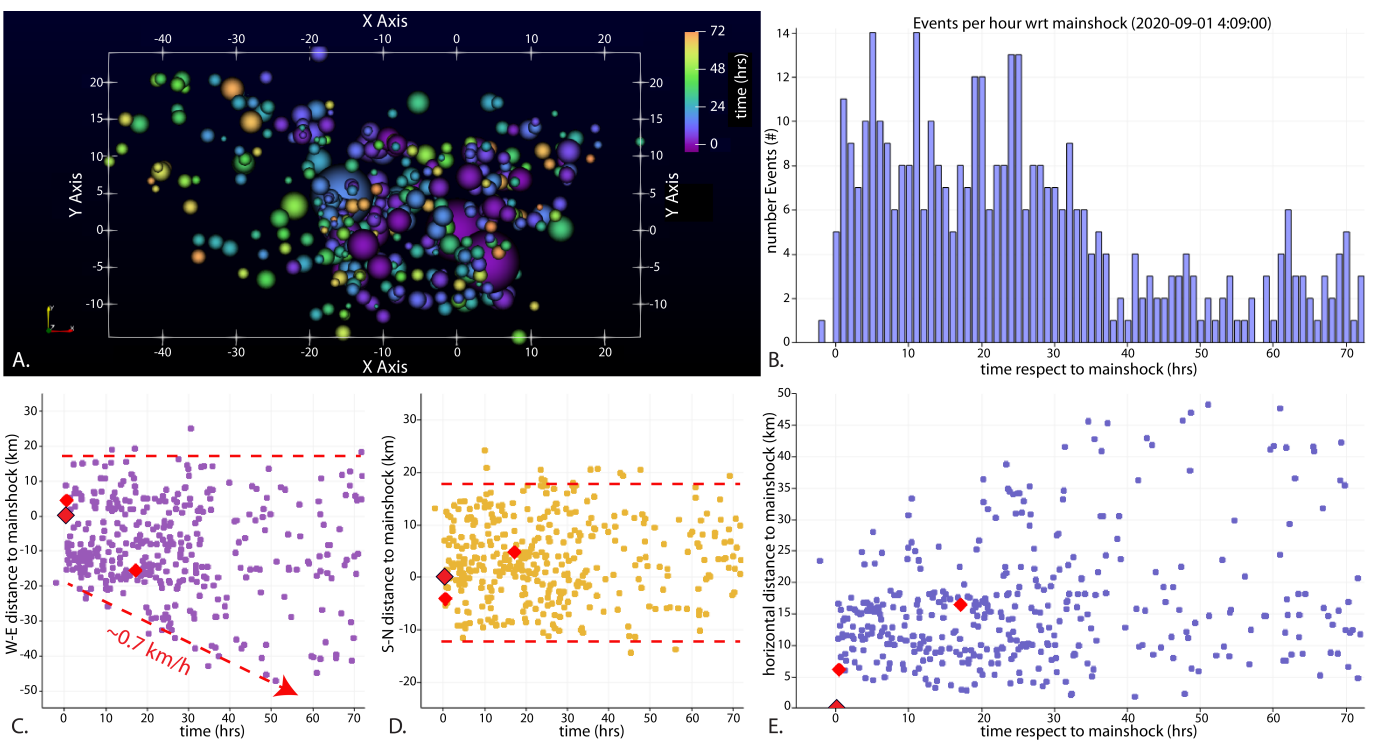

Figure 3. Analysis of the relocated catalog over the first $72 \mathrm{~h}$ after the mainshock; A. map view, distances are in $\mathrm{km}$, coordinate $(0,0)$ correspond to the mainshock and colours represent time; B. number of events/h, time is relative to the mainshock origin time. Bins are centered on the hour; $\mathrm{C}$. distance to mainshock in the West-East direction vs. time, in km; D. distance to mainshock in the South-North direction vs. time, in km; E. horizontal distance to main shock in $\mathrm{km}$. The 3 main events are highlighted by the red diamonds on subplots C, D E, the mainshock is black contoured. The red dashed lines on subplots $\mathrm{C}$ and D depict the seismicity boundaries.

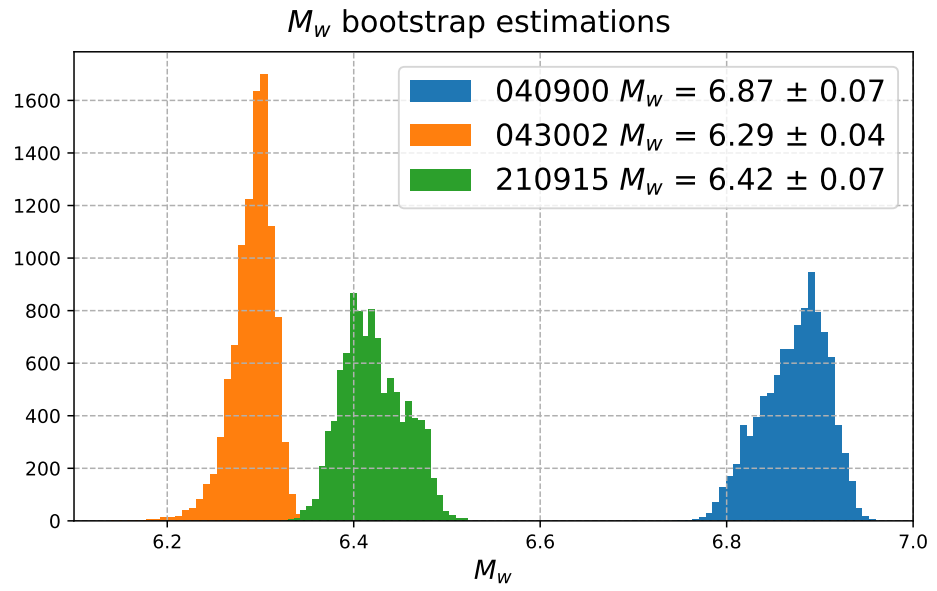

Figure 4. Histograms of the bootstrap analysis for the moment magnitude of the three largest events with $10^{5}$ inversions. Average $M_{w}$ and $\pm 2 \sigma$ uncertainties are given in the legend. 

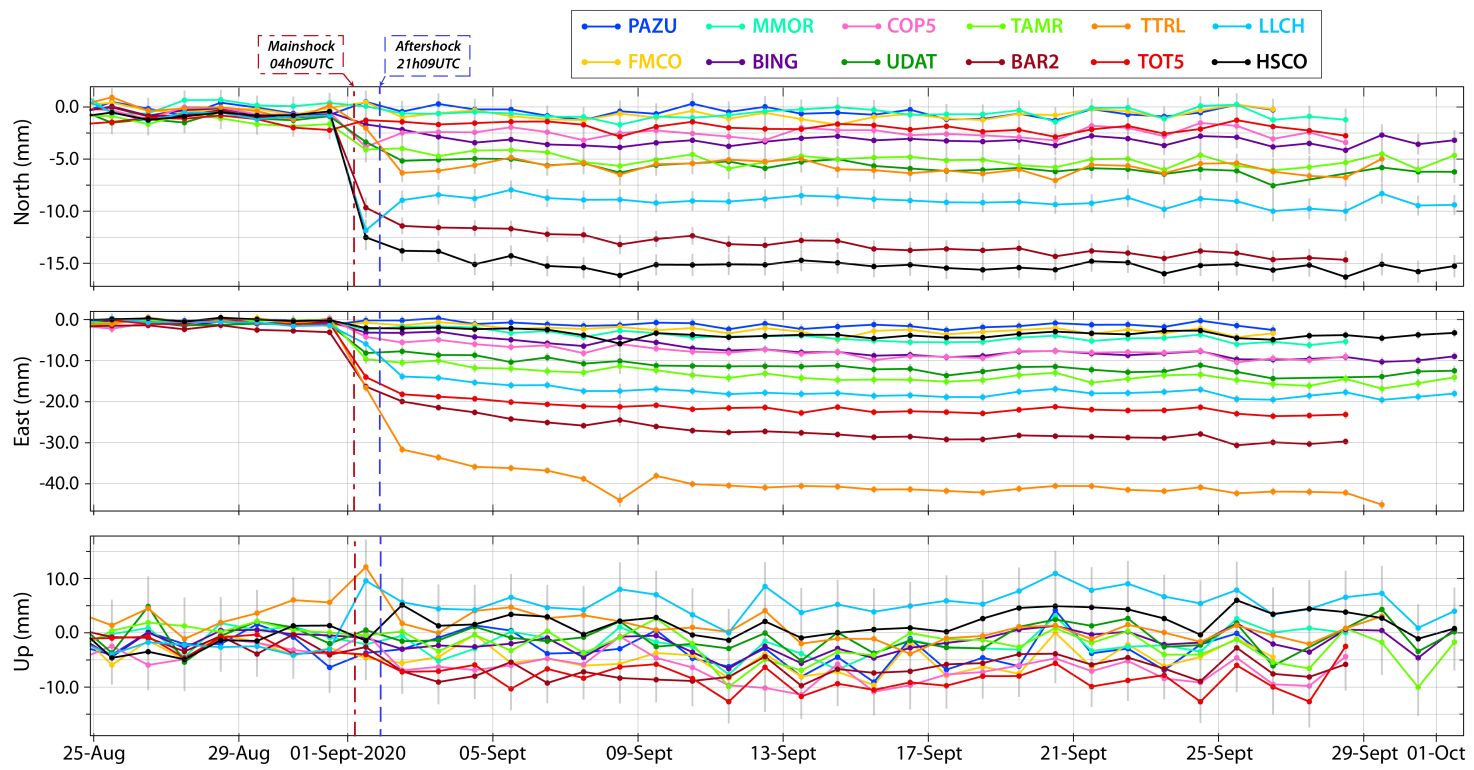

Figure 5. Time series of GPS daily positions from stations in the region of the sequence on the 3 components. The vertical black lines flag the exact time of the 2 events of September $1^{\text {st }}$, at the beginning of the sequence. 


\section{A. Mainshock - 01/09-4h09UTC}

B. Aftershock - 01/09 - 21h09UTC
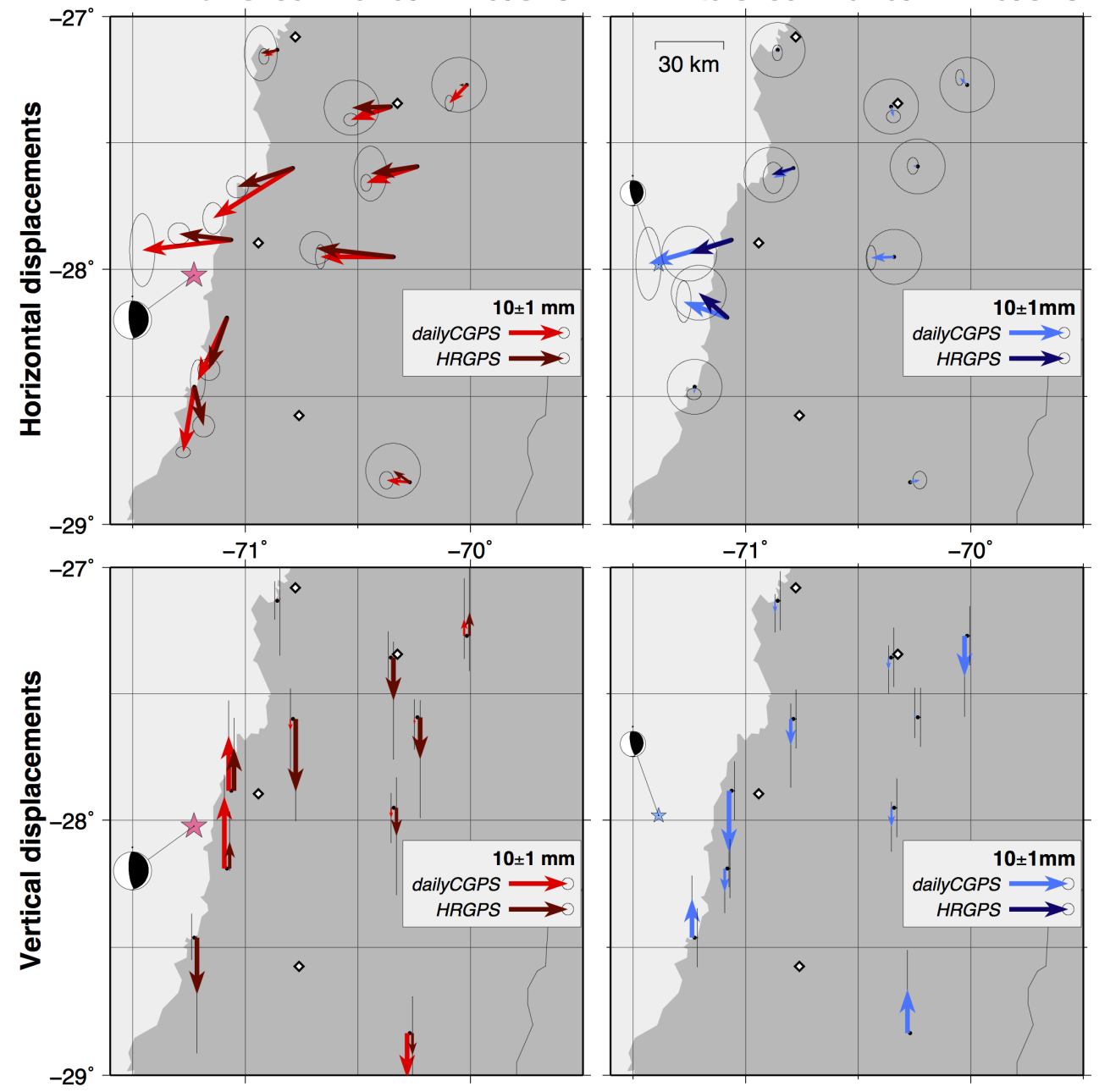

Figure 6. Comparison of 24 hours CGPS and HRGPS static co-seismic offset estimations; A. mainshock of 04:09 (reddish vectors) and B. aftershock of 21:09 (blueish vectors). Horizontal top row, vertical bottom row.

Earthquakes' locations from the relocated catalog and mechanisms from the W-phase analysis. 

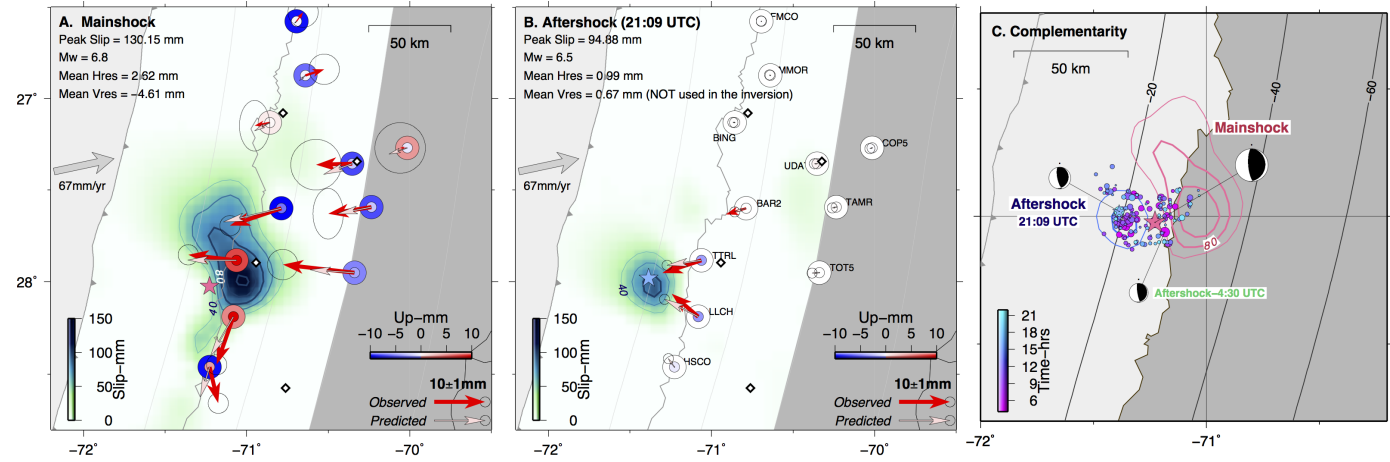

A.

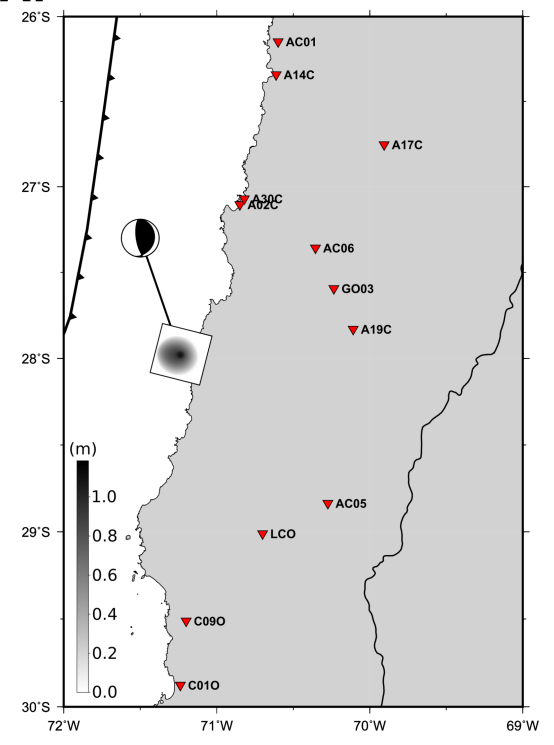

B.

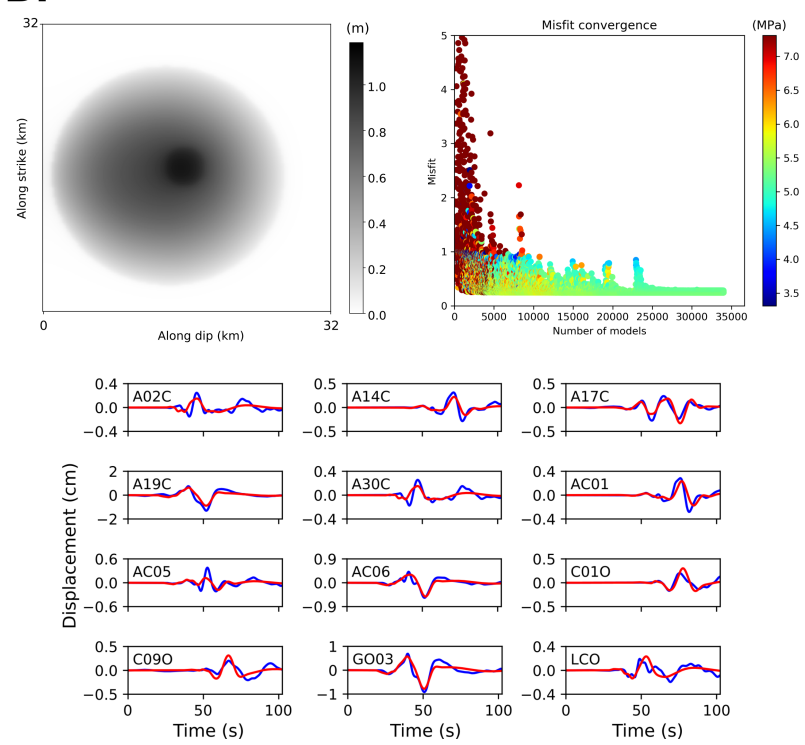

Figure 7. Slip distributions of A. the mainshock at 4:09 UTC inverted from the HRGPS (Fig. 6-A); B. the aftershock at 21:09 UTC inverted from the HRGPS (Fig. 6-B); Distributions are represented as the blue color scale (in mm), blue isolines are represented every $20 \mathrm{~mm}$; Horizontal coseismic displacements are depicted by arrows: Observations (red) vs predictions (pink); Vertical coseismic displacements are depicted by colored dots : Observations (big circles) vs predictions (small circles) with amplitude represented with the polar color scale; C. Zoom in to compare both slip distributions and the relocated catalog of aftershocks occurring between the 2 events represented with the color scale. Isodepth from Slab2.0 [Hayes et al., 2018]

Figure 8. Coseismic model of the mainshock obtained from the dynamic inversion. A. Geographic context of the mainshock rupture and stations used for modeling. The moment tensor was obtained from GCMT. B. Dynamic slip model on the fault plane and waveform misfit convergence colored with the stress drop. The bottom plot shows the E-W observed (blue) and modeled (red) waveforms of the best dynamic model. 
A.Total coseismic (Mainshock04h09UTC+Aftershock21 h09UTC)

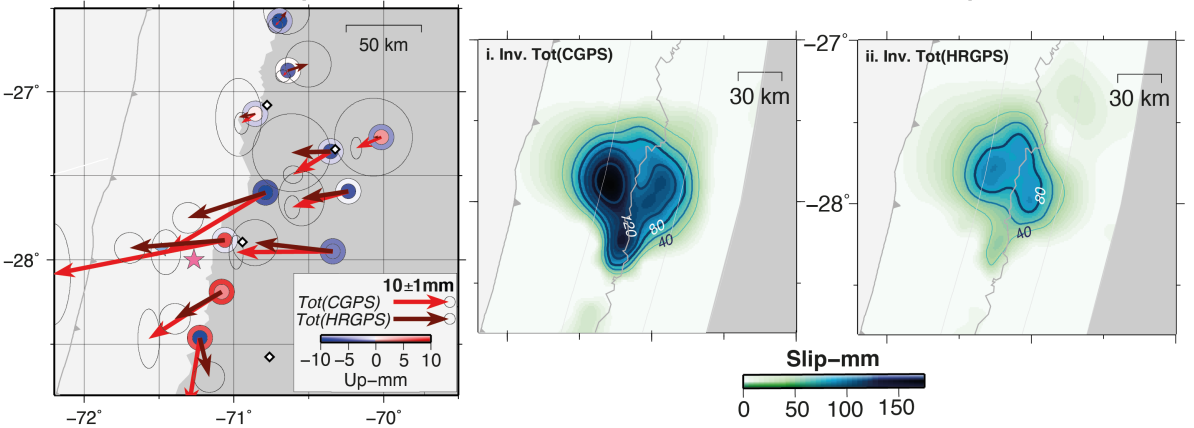

B.Early afterslip (difference [CGPS-HRGPS])
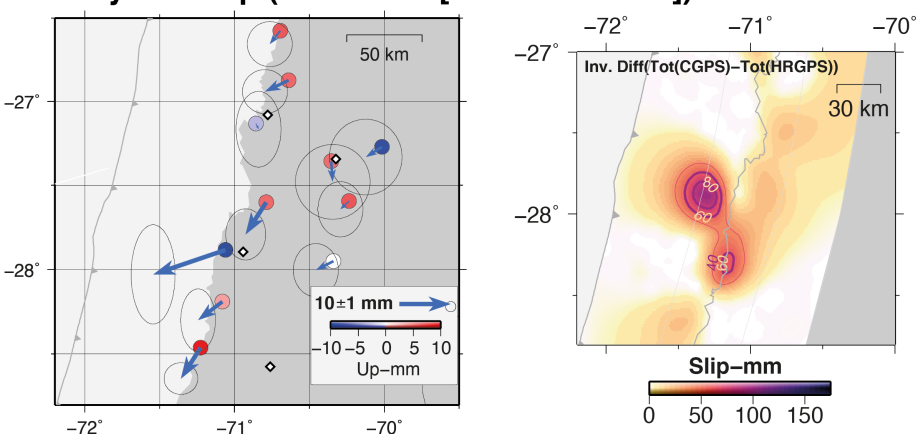

C. 22 days postseismic

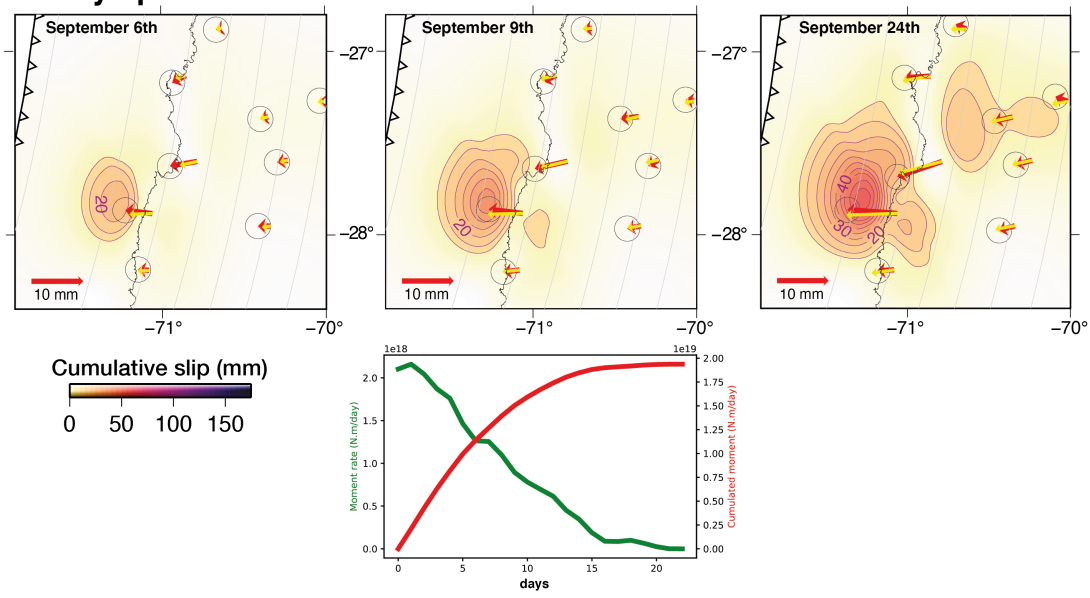

Figure 9. Slip history over the sequence: A. Total coseismic: vectors show the total coseismic displacement on September, $1^{\text {st }}$ (including both events and the aseismic slip that occurred during that period) measured by CGPS (light red) and the corresponding Slip distribution (i), compared with the total coseismic displacement due to the 2 events measured by HRGPS (dark red) and the corresponding slip distribution (ii);

B. Early afterslip estimated from the difference between CGPS and HRGPS estimates and the corresponding slip distribution; C. Slip-time dependent inversion of the postseismic deformation 22 days with 3 snapshots of the cumulative slip distribution. Yellow and red arrows are respectively model-predicted and observed displacements for CGPS sites recorded since the mainshock. Postseismic slip contours are every $10 \mathrm{~mm}$. Gray lines are Slab2.0 isodepth from Hayes et al. [2018]. 


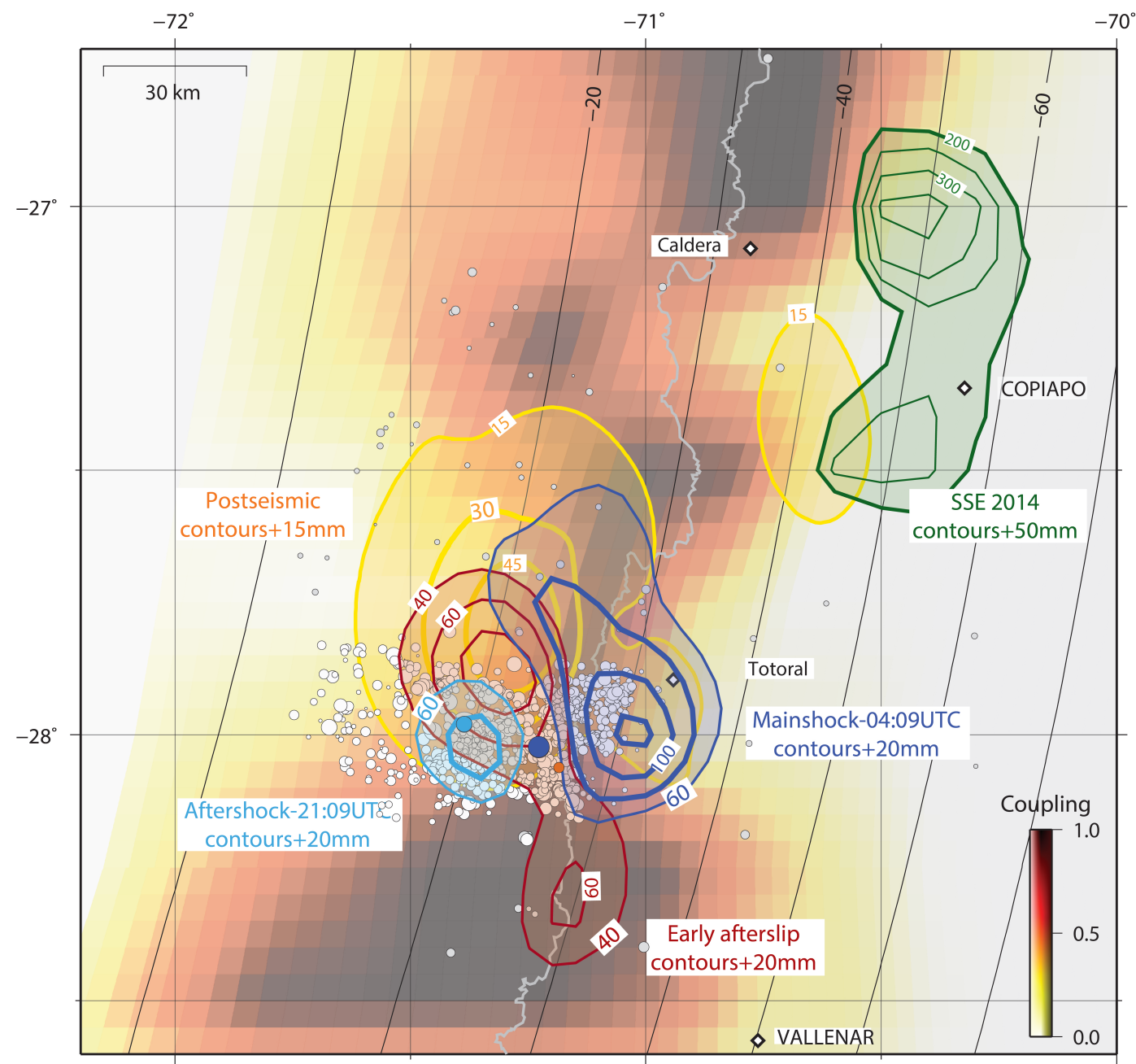

Figure 10. Slip distributions of the $M_{w}=6.9$ mainshock (01/09/2020-4:09 UTC, dark blue contours every $20 \mathrm{~mm}$ starting at 60mm), the $M_{w}=6.4$ aftershock (01/09/2020-21:09 UTC, light blue contours every $20 \mathrm{~mm}$ starting at $60 \mathrm{~mm}$ ); the rapid afterslip between the 2 events (red contours every $20 \mathrm{~mm}$ starting at $40 \mathrm{~mm}$ ), and 1 month of postseismic slip (yellow contours every $15 \mathrm{~mm}$ starting at $15 \mathrm{~mm}$ ). The epicenter of the $M_{w}=6.2$ aftershock (4:30 UTC) is depicted by the orange dot. Comparison with the coupling distribution in the region [Klein et al., 2018a] and the 2014 SSE distribution [Klein et al., 2018b, , represented by the dark green contours every $50 \mathrm{~mm}$ starting at $200 \mathrm{~mm}$ ). Background seismicity from relocated catalog depicted by white dots. Slab2.0 isodepth from Hayes et al. [2018] every $10 \mathrm{~km}$. 